patients was their unprompted admission that on this drug they felt generally better than previously.

In my limited experience of this new hypotensive agent it would appear to be a potent and useful drug for the common types of hypertension. Individual dose requirements appear to be wide but considerably lower than found by Peart and MacMahon. The critical dose level is narrow and it should be administered cautiously, starting with $5 \mathrm{mg}$. b.d. and increasing the dose by $5 \mathrm{mg}$. b.d. every three to seven days until a satisfactory response is reached.

The value of the drug is enhanced by its satisfactory hypotensive effect on the lying as well as the standing blood-pressure in all cases studied.-I am, etc.,

Roe Valley Hospital,

JAMES ROBERTSON.

$$
\text { Co. Londonderry. }
$$

\section{Treatment of Status Epilepticus}

StR,-I would agree entirely with your correspondents Drs. E. M. R. Critchley, G. O. M. Jones, and G. M. Levene (15 February, p. 437) that the help of anaesthetists is an invaluable advance in the treatment of status epilepticus. In the last three cases treated in this unit intubation was necessary, and in two full curarization was required by conditions accompanying the status. Such patients cannot be managed without expert anaesthetic help. However we still find intramuscular paraldehyde the drug of choice for early treatment, which may have to be initiated in the home. By the time a drip is set up the patient is likely to be in hospital and the choice of anticonvulsant can safely be wider. I should emphasize that the majority of cases should not reach the stage of requiring a drip, provided the condition is treated vigorously and the patient kept under adequate and continuous observation once status or even serial epilepsy commences. A striking lacuna in some of our cases has been the lack of adequate observation when the warning signal of frequent serial epilepsy or even a short bout of status has occurred. In these circumstances oral anticonvulsants may be difficult to take and no adequate parenteral substitute given. Status continues to be a medical emergency, which if not rapidly controlled requires hospital admission.-I am, etc.,

\section{Department of Neurology,}

$$
\text { C. W. M. Whitty. }
$$

\section{Drug Advertisements}

SIR,-In his letter in your issue of $8 \mathrm{Feb}-$ ruary (p. 374) Dr. J. Dobbing infers that I was making a comparison between the percentage of expenditure on advertising drugs to the medical profession and that on advertising "other merchandise." That was certainly not the implication intended by my letter.

He also states that he does not understand the relevance of my comparison between Communist-controlled countries and our system of free enterprise in respect of publicity for drugs. Surely this must lead to the conclusion that in these countries there is no freedom of choice, and in the eyes of the authorities no need to advertise any alternative methods of treatment other than those dictated by them.

If it were true, as The Guardian comments, that doctors do not prescribe proprietary preparations because of advertising, it is inconceivable that the drug manufacturers would continue to maintain their expenditure on advertising at its present level.-I am, etc.,

$$
\begin{aligned}
& \text { MaURICE Keating. } \\
& \text { Harley Publishing Co. Ltd., } \\
& \text { London W.C.2. }
\end{aligned}
$$

\section{Side-effect of Oral Contraceptives}

SIR,-I feel an unusual, and hitherto unrecorded, side-effect of oral contraception should be brought to the attention of other practitioners.

I prescribed " anovlar" tablets (norethisterone acetate $4 \mathrm{mg}$., ethinyl oestradiol $0.05 \mathrm{mg}$.), one daily from the 5 th to the $25 \mathrm{th}$ days of the menstrual cycle, to a patient with hitherto quite stable diabetes. After the third day of medication this became unstable as evinced by the reappearance of glycosuria, polyuria, and polydipsia, and increased insulin demand. The patient continued the anovlar for a few more days before consulting me ; the pill was then stopped. It was two menstrual cycles before she was again stabilized. I communicated by letter with the medical information department of Pharmethicals Ltd., the U.K. subsidiary of the manufacturers, Schering A.G. Berlin. They inform me that two or three other such cases have been reported, showing increased blood-sugar levels during treatment with anovlar. They suggest, therefore, that extreme care should be exercised when giving this preparation to diabetics and a careful check be kept on their urine, blood sugar, and insulin requirements. They also inform me that no case has been reported where anovlar has been considered directly responsible for a presenting diabetes mellitus in a previously healthy individual. It has been suggested that norethisterone acetate has some anabolic effect, therefore increasing appetite and dietetic intake.-I am, etc.,

Colchester, Essex.

N. L. Paros.

\section{Drugs and the Embryo}

SIR,-The results of the prospective study by Dr. R. W. Smithells and Miss Elizabeth R. Chinn (25 January, p. 217) on 219 pregnancies in which meclozine had been administered during the first 12 weeks of pregnancy is of considerable importance in providing further evidence that this drug is not associated with a higher foetal abnormality rate than usual. In a prospective and retrospective survey undertaken by the General Practitioner Research Group ${ }^{1}$ on 661 patients, in whom certain specified drugs had been taken in early pregnancy, a similar result was recorded. Thus of 214 patients who had received meclozine there was a foetal abnormality rate of $3.3 \%$, a miscarriage rate of $2.7 \%$, and a stillbirth rate of $0.5 \%$. We were also interested in other antihistamine drugs, and the next most commonly used was promethazine ( 165 cases), with a foetal abnormality rate of $4.3 \%$, which is not significantly different from normal. In our cases pheno- thiazines had not been used nearly so frequently as antihistamine drugs, but in 59 cases where trifluoperazine had been administered there was a foetal abnormality rate of $1.7 \%$, and in 43 patients given pipamazine the rate was $4.6 \%$, again a difference not significant in view of the relatively small numbers involved.

Other findings were an abnormality rate of $1.2 \%$ in association with 82 patients to whom dicyclomine, an anticholinergic drug, had been administered, and a rate of $6.6 \%$ in association with 61 patients given barbiturates. Foetal abnormalities occurred in $8.2 \%$ of 60 patients given female sex hormones and in $5.7 \%$ of 89 patients who had been $x$-rayed, these consisting mainly of chest films. In the case of barbiturates, female sex hormones, and $x$-rays, the trends for the figures indicate that significance at the $5 \%$ level might be expected if the samples were increased in size. Clearly it is of importance to extend the investigation to include larger numbers of patients falling into these categories.

Whilst it remains wise policy not to administer any drug during the early months of pregnancy unless it is absolutely necessary to do so it must be recalled that we have no knowledge of the effect of a severe untreated hyperemesis on the developing foetus, and that it may be better to use a drug to control symptoms than to chance possible harm to the foetus from this cause.-I am, etc.,

$$
\begin{aligned}
& \text { DAvid WheATLEY. } \\
& \text { The General Practitioner Research } \\
& \text { Group, } \\
& \text { Twickenham, Middlesex. }
\end{aligned}
$$

REFBRENCB

1 Practitioner, 1963, 191, 775.

\section{Inhaled Ergotamine for Migraine}

SIR,-The article by Dr. J. Crooks, Dr. S. A. Stephen, and Dr. W. Brass (25 January, p. 221) on a clinical trial using inhaled ergotamine tartrate as a treatment for migraine is a very valuable addition to the somewhat unsuccessful treatment of this most unpleasant condition. I would like to support their conclusions from my own personal experience.

Having suffered from migraine for over ten years, I have tried most methods of treatment. I found "cafergot" tablets gave very little relief ; "migril" tablets were somewhat better, especially if combined with an extra $25 \mathrm{mg}$. of " largactil" (chlorpromazine); ergotamine tartrate intramuscularly afforded" most relief, but required $50 \mathrm{mg}$. of chlorpromazine intramuscularly to prevent excessive nausea.

When I was presented with a "medihalerergotamine" I naturally made use of it at the first opportunity and was extremely gratified by the results, and have continued to use it as required ever since. In twelve attacks the medihaler has never failed to relieve the headache completely after two inhalations, and in all instances save two the nausea of the migraine was relieved.

I am now convinced that the medihalerergotamine is the treatment of choice for migraine, perhaps combined with a $25-\mathrm{mg}$. tablet of chlorpromazine for any residual nausea.-I am, etc.,

\section{Sir Patrick Dun's Hospital,} W. H. Beesley. 